\title{
IDegLira Improves Glycemic Control in Japanese Patients with Uncontrolled Type 2 Diabetes on Premixed Insulin Therapy
}

\author{
Hirotaka Watada · Bue F. Ross Agner - Ankur Doshi · Lars Bardtrum • \\ Mattis Flyvholm Ranthe · Liana K. Billings
}

Received: September 12, 2019 / Published online: November 23, 2019

(C) The Author(s) 2019

\begin{abstract}
Introduction: DUAL II Japan (NCT02911948) was a 26-week, phase 3a randomized, treat-totarget trial which compared the efficacy and safety of IDegLira with degludec in 210 Japanese patients with type 2 diabetes (T2D) uncontrolled on premixed or basal insulin therapy. The DUAL II Japan trial presented the opportunity for a post hoc analysis to examine the
\end{abstract}

Enhanced Digital Features To view enhanced digital features for this article go to https://doi.org/10.6084/ m9.figshare.10260689.

Electronic Supplementary Material The online version of this article (https://doi.org/10.1007/s13300019-00730-y) contains supplementary material, which is available to authorized users.

H. Watada $(\bowtie)$

Department of Metabolism and Endocrinology, Juntendo University, Tokyo, Japan

e-mail: hwatada@juntendo.ac.jp

B. F. Ross Agner - L. Bardtrum · M. F. Ranthe

Novo Nordisk A/S, Søborg, Denmark

A. Doshi

PrimeCare Medical Group, Houston, TX, USA

L. K. Billings

NorthShore University HealthSystem, Skokie, IL, USA

L. K. Billings

University of Chicago Pritzker School of Medicine,

Skokie, IL, USA safety and efficacy of switching patients from a premixed regimen (containing both basal and bolus insulin components) to IDegLira.

Methods: Patients from DUAL II Japan were stratified according to prior insulin regimen (premixed or basal insulin). The following endpoints were assessed in this post hoc analysis by pre-trial insulin regimen: change in $\mathrm{HbA}_{1 \mathrm{c}}$, body weight, daily total insulin dose, nine-point self-measured blood glucose, and severe or blood glucose-confirmed hypoglycemia (defined as severe or plasma glucose less than $56 \mathrm{mg} / \mathrm{dL}$ ).

Results: This post hoc analysis included 39 patients who switched from premixed insulin to IDegLira. The treatment effect in this population was independent of insulin type at baseline (premixed or basal; interaction test, $P=0.2535$ ). In patients switching from premixed insulin to IDegLira, mean [standard deviation (SD)] $\mathrm{HbA}_{1 \mathrm{c}}$ was $8.26 \%(0.73)$ at baseline and $6.68 \%(0.93)$ at week 26. Mean (SD) body weight was reduced by $1.5(2.9) \mathrm{kg}$. At week 26, daily insulin dose was 34.2 dose steps. After 26 weeks, the mean prandial increment was smaller at all meals with IDegLira irrespective of pre-trial insulin regimen. Rate of hypoglycemic events was 2.59 events/patient-year of exposure over the 26 weeks.

Conclusion: This post hoc study is the first to evaluate the switch from premixed insulin to IDegLira in patients with uncontrolled T2D. IDegLira initiation resulted in improved $\mathrm{HbA}_{1 \mathrm{c}}$ 
and weight loss. This study offers insight into the effectiveness and safety of switching patients from premixed insulin therapy to IDegLira, and provides support for further investigation.

Trial Registration: NCT02911948.

Keywords: Basal insulin; Hypoglycemia; Liraglutide; Premixed insulin; Randomized trial; Type 2 diabetes

\section{Key Summary Points}

\section{Why carry out this study?}

The DUAL II Japan trial compared the efficacy and safety of IDegLira with degludec in Japanese patients with type 2 diabetes (T2D) uncontrolled on basal or premixed insulin therapy

The DUAL II Japan trial presented the opportunity for a post hoc analysis to examine the safety and efficacy of transitioning patients from a premixed regimen (containing both basal and bolus insulin components) to IDegLira

\section{What was learned from the study?}

In patients treated previously with premixed insulin, IDegLira initiation resulted in improved $\mathrm{HbA}_{1 \mathrm{C}}$ and weight loss

This is the first study to offer insight into the effectiveness and safety of switching patients from premixed insulin therapy to IDegLira

This post hoc evaluation provides support for further investigation into switching treatment from premixed insulin to IDegLira in patients with T2D

\section{INTRODUCTION}

Type 2 diabetes (T2D) is a chronic disease caused by insulin resistance and a decline in beta cell function. As a result of the progressive nature of T2D, many patients eventually require insulin therapy [1]. Although basal and premixed insulin, in combination with oral agents, are established treatments for T2D, many patients treated with these agents fail to achieve adequate glycemic control [2]. As such, when prandial control is needed for patients with progressed T2D, options are limited and often include high complexity regimens, such as basal-bolus treatment.

Insulin degludec/liraglutide (IDegLira)—a fixed-ratio combination of the basal insulin, insulin degludec (degludec) and the glucagonlike peptide 1 receptor agonist (GLP-1RA), liraglutide-is emerging as an effective oncedaily treatment option for patients requiring insulin initiation/intensification. This single pen combination product provides the ability to control fasting plasma glucose and postprandial plasma glucose in a single injection, with reduced insulin dose and better weight management compared with basal insulin and even basal-bolus treatment [3-5]. Successful outcomes, including a mean $\mathrm{HbA}_{1 \mathrm{c}}$ below $7.0 \%$ $(53 \mathrm{mmol} / \mathrm{mol})$ at end of trial, have been demonstrated with IDegLira in the global phase 3 DUAL clinical trial program [3, 5-13]. Recently, the DUAL VIII trial investigated the durability of IDegLira versus insulin glargine 100 units/mL (IGlar U100) [defined as $\mathrm{HbA}_{1 \mathrm{c}}$ of $7.0 \%(53 \mathrm{mmol} / \mathrm{mol})$ or higher at two consecutive visits from week 26] and demonstrated that IDegLira had a longer durability than IGlar U100. Treatment needed to be intensified much sooner with IGlar U100 (approximately 1 year) compared with over 2 years with IDegLira [13].

Data are needed to help healthcare providers choose therapy intensification in patients who are already on insulin therapies and have $\mathrm{HbA}_{1 \mathrm{c}}$ levels above treatment target. Often, one considered step is the use of basal-bolus insulin treatment regimens, which can unfortunately have high complexity and burden for patients. Importantly, the DUAL VII trial investigated the 
efficacy and safety of IDegLira versus basalbolus therapy and showed non-inferior reduction in $\mathrm{HbA}_{1 \mathrm{c}}$, lower hypoglycemia rates, weight loss, and less treatment burden versus basal-bolus therapy in patients requiring prandial control [5]. The data from the DUAL VII trial showed that basal-bolus therapy may not be the best intensification option for patients with $\mathrm{HbA}_{1 \mathrm{c}}$ over $7.0 \%(53 \mathrm{mmol} / \mathrm{mol})$ on basal insulin [5]. Conversely, the safety and efficacy of transitioning patients on a basal-bolus regimen to a fixed-ratio combination, such as IDegLira, has not been shown.

Therefore, the DUAL II Japan trial offered the opportunity for a post hoc analysis that could examine the safety and efficacy of transitioning patients from a premixed regimen (containing both basal and bolus insulin components) to IDegLira. DUAL II Japan was a 26-week, phase $3 \mathrm{a}$ randomized, treat-to-target trial that compared the efficacy and safety of IDegLira with degludec in 210 Japanese patients with T2D uncontrolled on basal or premixed insulin therapy [14]. Results demonstrated that IDegLira was superior to degludec in terms of change from baseline in $\mathrm{HbA}_{1 \mathrm{c}}$ with an estimated treatment difference of $-1.28 \%$-points [95\% CI - 1.50; - 1.06] $(-13.98 \mathrm{mmol} / \mathrm{mol}$ [95\% CI- 16.41; - 11.55], $P<0.0001)$.

In order to inform on the practicality of switching patients uncontrolled on premixed insulin to IDegLira, this post hoc analysis presents efficacy and safety data, according to pretrial insulin regimen (premixed or basal insulin), for Japanese patients who switched to IDegLira compared with those who switched to degludec.

\section{METHODS}

This was a post hoc analysis of the DUAL II Japan trial (NCT02911948). The methodology and results of DUAL II Japan have been reported previously [14]. In brief, DUAL II Japan was a 26-week randomized, two-arm, parallel, doubleblinded, multicenter, treat-to-target trial that compared the efficacy and safety of IDegLira with degludec in Japanese patients with T2D [14]. Patients were Japanese adults with a body mass index of at least $23 \mathrm{~kg} / \mathrm{m}^{2}, \mathrm{HbA}_{1 \mathrm{c}}$ of 7.5-11.0\% (58-97 $\mathrm{mmol} / \mathrm{mol})$, who were inadequately controlled with basal or premixed insulin therapy in combination with metformin with or without an oral antidiabetic drug (OAD, stable daily dose 20-50 units (U), both inclusive, for at least 60 days prior to screening) [14].

Patients were stratified according to prior OAD and insulin treatment regimen [14]. The recommended starting dose for both IDegLira and degludec was $10 \mathrm{U}$, with an option of increasing the starting dose up to $16 \mathrm{U}$ at the investigators' discretion, based on the patient's conditions (e.g., previous insulin dose or level of glycemic control). The dose of IDegLira and degludec was titrated twice-weekly in increments of \pm 2 based on the mean of three consecutive pre-breakfast self-measured blood glucose (SMBG) values aiming for a mean plasma glucose of $72 \mathrm{mg} / \mathrm{dL}(4.0 \mathrm{mmol} / \mathrm{L})$ and $90 \mathrm{mg} / \mathrm{dL}(5.0 \mathrm{mmol} / \mathrm{L})$. The maximum daily dose was $50 \mathrm{U}$ for both degludec and IDegLira, which was also the maximum dose for IDegLira in all phase 3 trials $[3-6,8,9,11,13,15]$.

The primary endpoint of DUAL II Japan was change from baseline in $\mathrm{HbA}_{1 \mathrm{c}}$ after 26 weeks. The following endpoints were assessed in this post hoc analysis by pre-trial insulin regimen: change in $\mathrm{HbA}_{1 \mathrm{c}}$, change in body weight, daily total insulin dose, nine-point SMBG, and severe or blood glucose-confirmed hypoglycemia. Safety parameters were also assessed. SMBG was assessed using a blood glucose meter calibrated to plasma equivalent values. Hypoglycemic events consisted of either blood glucose-confirmed symptomatic events [plasma glucose level less than $3.1 \mathrm{mmol} / \mathrm{L}(56 \mathrm{mg} / \mathrm{dL})]$ with symptoms consistent with hypoglycemia) and/ or severe episodes requiring third-party assistance. The protocol was approved by independent ethics committees or institutional review boards at all participating institutions. All procedures performed in studies involving human participants were in accordance with the ethical standards of the institutional and/or national research committee and with the 1964 Helsinki declaration and its later amendments or comparable ethical standards. Informed consent was obtained from all individual participants included in the study. 


\section{Statistical Analysis}

Results for the subgroup analysis assessing if results for change in $\mathrm{HbA}_{1 \mathrm{c}}$ were affected by pretrial insulin regimen (i.e., premixed or basal insulin) were analyzed using an analysis of covariance (ANCOVA) model with treatment, pre-trial insulin regimen, and interaction between treatment and pre-trial insulin regimen as fixed factors, and baseline response as covariate. All other results were presented descriptively, with no formal statistical comparison performed. Missing data were imputed using last observation carried forward.

\section{RESULTS}

This post hoc evaluation includes data for a subset of 39 and 38 patients who switched from premixed insulin to IDegLira and degludec, respectively; data are also presented for 66 and 67 patients who switched from basal insulin to IDegLira and degludec, respectively. No patients withdrew from the IDegLira arm. Seven patients withdrew from the degludec arm; of these, three patients switched from premixed insulin and four patients switched from basal insulin.

Demographics and baseline characteristics by pre-trial insulin regimen are shown in Table 1. The subset of patients pre-treated with premixed and basal insulins had mean [standard deviation (SD)] $\mathrm{HbA}_{1 \mathrm{c}}$ at baseline of $8.26 \%$ (0.73) $(66.78 \mathrm{mmol} / \mathrm{mol}$ [7.98]) and $8.81 \%$ (0.91) $(72.79 \mathrm{mmol} / \mathrm{mol}$ [9.95]) in the IDegLira arm, and $8.34 \%(0.68)(67.65 \mathrm{mmol} / \mathrm{mol}[7.43])$ and $8.69 \%(0.84)(71.48 \mathrm{mmol} / \mathrm{mol}$ [9.18]) in the degludec arm, respectively. For patients previously treated with premixed insulin, the mean duration of diabetes was 17.5 years and 16.5 years, in the IDegLira and degludec arms, respectively. For patients previously treated with basal insulin, the mean duration of diabetes was 12.5 years and 12.2 years, in the IDegLira and degludec arms, respectively.

In all subsets, mean $\mathrm{HbA}_{1 \mathrm{c}}$ decreased during the trial. After 26 weeks of treatment, mean $\mathrm{HbA}_{1 \mathrm{c}}$ in the premixed insulin subset decreased from $8.26 \%(0.73)(66.78 \mathrm{mmol} / \mathrm{mol}$ [7.98]) at baseline to $6.68 \% \quad(0.93) \quad(49.51 \mathrm{mmol} / \mathrm{mol}$
[10.16]) at end-of-trial (EOT) with IDegLira, and $8.34 \%(0.68)(67.65 \mathrm{mmol} / \mathrm{mol}$ [7.43]) to $8.18 \%$ (1.03) $(65.90 \mathrm{mmol} / \mathrm{mol}$ [11.26]) with degludec (Fig. 1a). Mean $\mathrm{HbA}_{1 \mathrm{c}}$ in the basal insulin subset decreased from $8.81 \%(0.91)(72.79 \mathrm{mmol} / \mathrm{mol}$ [9.95]) at baseline to $6.64 \% \quad(0.72)$ (49.07 $\mathrm{mmol} / \mathrm{mol}$ [7.87]) at EOT with IDegLira, and $8.69 \%(0.84)(71.48 \mathrm{mmol} / \mathrm{mol}$ [9.18]) to $7.77 \%$ (1.04) $(61.42 \mathrm{mmol} / \mathrm{mol}$ [11.37]) with degludec, after 26 weeks (Fig. 1a). The interaction between treatment and pre-trial insulin regimen was not statistically significant (premixed or basal; interaction test, $P=0.2535$ ), which indicated that the treatment difference for change in $\mathrm{HbA}_{1 \mathrm{c}}$ was not affected by pre-trial insulin regimen.

Mean (SD) body weight was reduced in the patient subsets pre-treated with premixed and basal insulin in the IDegLira arm $(-1.5 \mathrm{~kg}$ [2.9] and $-0.3 \mathrm{~kg}$ [3.7], respectively), as compared with weight gain for the subsets in the degludec arm $(+0.1 \mathrm{~kg}$ [2.8] and $+1.1 \mathrm{~kg}$ [2.7], respectively; Fig. 1b).

Mean daily IDegLira doses at EOT in the premixed and basal insulin subsets were 34.2 dose steps (34.2 U degludec and $1.2 \mathrm{mg}$ liraglutide) and 39.6 dose steps (39.6 U degludec and $1.4 \mathrm{mg}$ liraglutide) in the IDegLira arm compared with $39.4 \mathrm{U}$ and $42.2 \mathrm{U}$ in the degludec arm, respectively (Fig. S1 in the supplementary material).

In the subset of patients inadequately controlled with premixed insulin at baseline, the mean SMBG values decreased more with IDegLira than with degludec after 12 weeks (Fig. S2 in the supplementary material). After 26 weeks, the mean prandial increment was smaller at all meals with IDegLira irrespective of pre-trial insulin regimen (Table $S 1$ in the supplementary material). Postprandial SMBG levels improved in all patients who switched to IDegLira (Fig. S2 in the supplementary material).

The corresponding rates for patients who experienced severe or blood glucose-confirmed hypoglycemic episodes in the premixed and basal insulin subsets were 2.59 and 2.11 episodes per patient-year of exposure (PYE) with IDegLira, compared with 3.97 and 1.04 episodes per PYE with degludec, respectively (Table S2 in the supplementary material). 
Table 1 Baseline characteristics by pre-trial insulin regimen

\begin{tabular}{|c|c|c|c|c|}
\hline \multirow{2}{*}{$\begin{array}{l}\text { Pre-trial insulin regimen } \\
\text { Trial insulin regimen }\end{array}$} & \multicolumn{2}{|c|}{ Premixed insulin } & \multicolumn{2}{|l|}{ Basal insulin } \\
\hline & IDegLira & Degludec & IDegLira & Degludec \\
\hline Full analysis set & $39^{a}$ & $38^{\mathrm{b}}$ & 66 & 67 \\
\hline Age, years & $60.2(10.7)$ & $59.7(8.7)$ & $54.4(9.7)$ & $53.2(9.9)$ \\
\hline Duration of diabetes, years & $17.5(7.8)$ & $16.5(7.5)$ & $12.5(7.2)$ & $12.2(7.0)$ \\
\hline Daily dose of pre-trial insulin, $U$ & $14.1(3.4)$ & $15.6(2.6)$ & $15.2(2.9)$ & $15.9(3.0)$ \\
\hline Male, \% & 69.2 & 50.0 & 65.2 & 65.7 \\
\hline Body weight, kg & $71.9(11.3)$ & $71.5(13.4)$ & $75.1(12.1)$ & $77.8(13.9)$ \\
\hline BMI, $\mathrm{kg} / \mathrm{m}^{2}$ & $26.5(2.7)$ & $27.5(4.5)$ & $27.7(3.3)$ & $28.4(4.3)$ \\
\hline $\mathrm{FPG}, \mathrm{mmol} / \mathrm{L}$ & $9.5(2.7)$ & $8.8(3.0)$ & $8.6(2.5)$ & $8.5(2.2)$ \\
\hline $\mathrm{FPG}, \mathrm{mg} / \mathrm{dL}$ & $171.9(48.9)$ & $159.3(53.8)$ & $155.1(45.0)$ & $153.5(40.1)$ \\
\hline $\mathrm{HbA}_{1 c}, \mathrm{mmol} / \mathrm{mol}$ & $66.8(8.0)$ & $67.6(7.4)$ & $72.8(10.0)$ & $71.4(9.1)$ \\
\hline $\mathrm{HbA}_{1 \mathrm{c}}, \%$ & $8.3(0.7)$ & $8.3(0.7)$ & $8.8(0.9)$ & $8.7(0.8)$ \\
\hline
\end{tabular}

Full analysis set. Data are mean (SD) values

$B M I$ body mass index, degludec insulin degludec, $F P G$ fasting plasma glucose, $H b A_{l c}$ glycated hemoglobin, IDegLira insulin degludec/liraglutide, $S D$ standard deviation, $U$ unit

${ }^{a}$ Seven of the 39 patients in the premixed subgroup were receiving insulin degludec/insulin aspart

${ }^{\mathrm{b}}$ Nine of the 38 patients in the premixed subgroup were receiving insulin degludec/insulin aspart

The percentages of patients experiencing at least one adverse event (AE) were comparable in each treatment arm, regardless of pre-treatment regimen (Table S3 in the supplementary material). As expected with a GLP-1RA-based treatment regimen, the rate of gastrointestinal AEs was higher in the IDegLira group versus the degludec group. Three patients (2.9\%) reported a total of four serious AEs (SAEs) with IDegLira compared with four patients $(3.8 \%)$ reporting a total of six SAEs with degludec; details are reported in the primary analysis (Table S3 in the supplementary material) of [14].

\section{DISCUSSION}

This post hoc analysis represents the first study to specifically evaluate the switch to IDegLira in a subset of patients with T2D who were uncontrolled on premixed insulin plus metformin (with or without one additional OAD). This study provides insight into transitioning patients from a regimen that contains basal and bolus insulin components (premixed) to a fixedratio combination of a GLP-1RA and basal insulin, IDegLira. Overall, the findings showed that patients on premixed insulin can have improvements in blood glucose levels without increasing complexity, causing weight gain, or increasing rates of hypoglycemia.

Consistent with the results of the primary analysis, which demonstrated a superior change in $\mathrm{HbA}_{1 \mathrm{c}}$ with IDegLira versus degludec [14], and regardless of pre-trial insulin regimen (premixed or basal insulin), results of this post hoc analysis demonstrated a numerically greater reduction in $\mathrm{HbA}_{1 \mathrm{c}}$ from baseline with IDegLira versus degludec. The results of an interaction test for change in $\mathrm{HbA}_{1 \mathrm{c}}$ after 26 weeks, $(P=0.2535)$ indicated that the treatment difference was not different in each of the pre-trial treatment groups.

Additional findings regarding weight change, hypoglycemia, and SMBG levels are 


\begin{tabular}{|c|c|c|c|c|}
\hline \multirow[b]{2}{*}{$N=$} & \multicolumn{2}{|c|}{ Premixed-insulin } & Basal insulin & $\begin{array}{l}\text { Deglud } \\
\text { sulin }\end{array}$ \\
\hline & 39 & 38 & 66 & 67 \\
\hline $\begin{array}{l}\mathrm{HbA}_{1 \mathrm{c}} \text { at } \\
\text { baseline, } \% \\
(\mathrm{mmol} / \mathrm{mol})\end{array}$ & $\begin{array}{c}8.26 \\
(66.78)\end{array}$ & $\begin{array}{c}8.34 \\
(67.65)\end{array}$ & $\begin{array}{c}8.81 \\
(72.79)\end{array}$ & $\begin{array}{c}8.69 \\
(71.48)\end{array}$ \\
\hline $\begin{array}{l}\text { End of trial, \% } \\
(\mathrm{mmol} / \mathrm{mol})\end{array}$ & $\begin{array}{c}6.68 \\
(49.51)\end{array}$ & $\begin{array}{c}8.18 \\
(65.90)\end{array}$ & $\begin{array}{c}6.64 \\
(49.07)\end{array}$ & $\begin{array}{c}7.77 \\
(61.42)\end{array}$ \\
\hline
\end{tabular}

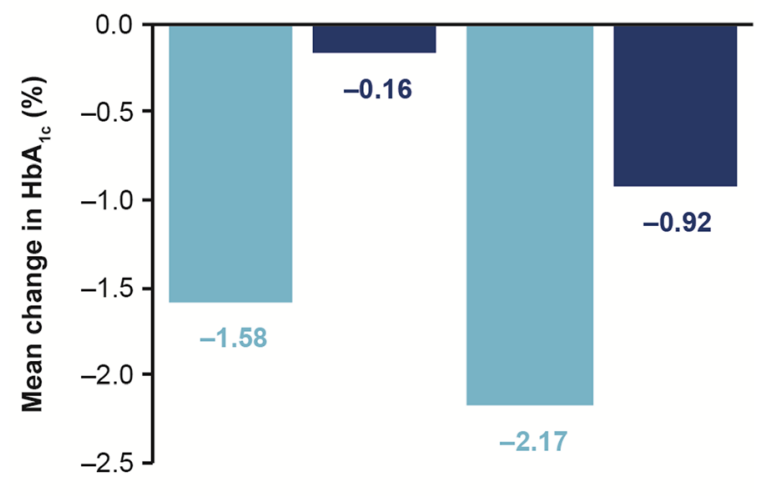

\begin{tabular}{lcccc} 
b & \multicolumn{2}{c}{ Premixed-insulin } & \multicolumn{2}{c}{ Basal insulin } \\
$\quad N=$ & 39 & 38 & 66 & 67 \\
$\begin{array}{l}\text { Body } \\
\text { weight at } \\
\text { baseline, kg }\end{array}$ & 71.9 & 71.5 & 75.1 & 77.8 \\
$\begin{array}{l}\text { End of trial, } \\
\text { kg }\end{array}$ & 70.4 & 71.6 & 74.9 & 78.9 \\
& & & &
\end{tabular}

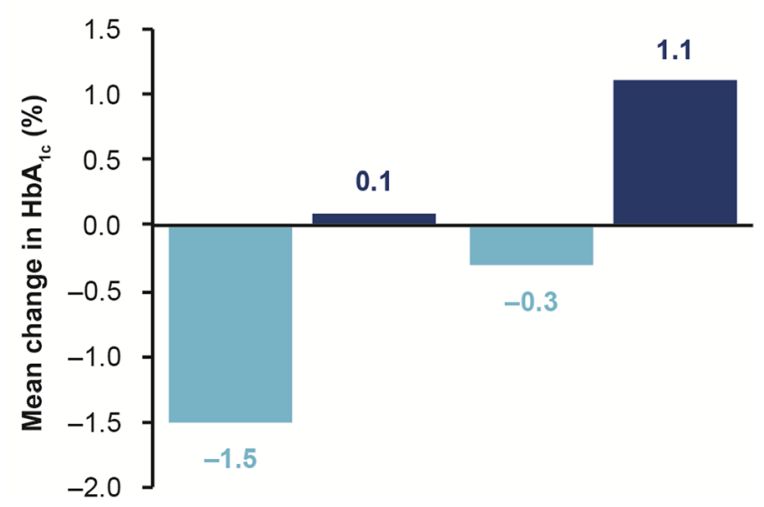

Fig. 1 Mean change from baseline to week 26 in a $\mathrm{HbA}_{1 \mathrm{c}}$ (\%) and $\mathbf{b}$ body weight $(\mathrm{kg})$ by pre-trial insulin regimen. Data are mean values. Missing data were imputed using last observation carried forward. Degludec insulin degludec, $\mathrm{HbA}_{1 \mathrm{c}}$ glycated hemoglobin, IDegLira insulin degludec/ liraglutide

also valuable in determining the utility of transitioning a patient from premixed insulin to
IDegLira. In patients treated previously with premixed insulin there was more weight loss/ less weight gain than for patients treated previously with basal insulin, irrespective of the trial treatment. The mean prandial SMBG increment across all meals was improved with IDegLira compared with patients previously treated with premixed insulin. In contrast, patients who switched from premixed insulin to degludec did not show improvements in prandial SMBG. These findings indicated that patients on premixed insulin, with a basal-bolus component, where postprandial control would be expected, had further improvements with IDegLira. Moreover, transitioning patients from premixed insulin to an optimally-titrated basal insulin did not improve the postprandial blood glucose excursion. These findings aligned with data showing that GLP-1RA treatment helped to reduce postprandial glucose excursions [16]. The improvement in glycemic control observed with IDegLira was achieved with a numerically lower insulin dose than with degludec, regardless of pre-trial insulin regimen. These data show that intensifying therapy from a premixed insulin to a fixed-ratio of basal insulin and GLP-1RA is more efficacious and safe than switching to basal insulin alone. Furthermore, these data suggest that IDegLira may be an appropriate treatment choice in lieu of a more complex basal-bolus regimen in patients who have uncontrolled blood glucose on premixed insulin. In terms of safety, a higher rate of hypoglycemia was observed in patients previously treated with premixed insulin at baseline compared with basal insulin, regardless of which randomized treatment patients were receiving.

No unexpected safety or tolerability issues were observed with IDegLira in patients previously treated with premixed or basal insulin regimens, and the findings regarding a higher incidence of gastrointestinal AEs in the IDegLira group was consistent with the safety profile of liraglutide [17].

In the overall study, patients were randomized to receive IDegLira and degludec; however, differences between premixed and basal insulin regimens should be interpreted with care, as patients were not randomized to pre-trial 
treatment. The small study population was a limitation of this analysis, and due to this, no formal statistical comparison between treatments was conducted. Nonetheless, a comparison of the efficacy data with IDegLira versus degludec indicated that the improvements observed in patients switching from premixed insulin to IDegLira was not due to an overall trial effect. This post hoc analysis offers insight into the effectiveness and safety of switching patients from premixed insulin therapy to IDegLira, and provides support for further investigation into this switch.

\section{CONCLUSION}

This post hoc analysis, the first to evaluate the switch from premixed insulin to IDegLira in patients with uncontrolled T2D, demonstrated that IDegLira initiation resulted in improved $\mathrm{HbA}_{1 \mathrm{c}}$, with underlying improvements of both fasting and prandial glucose and accompanied by weight loss.

\section{ACKNOWLEDGEMENTS}

The authors thank the investigators, research coordinators, and patients in the trial.

Funding. This study and the Rapid Service Fee were funded by Novo Nordisk.

Medical Writing and Editorial Assistance. The authors thank Sejal Varsani and Catherine Jones (Watermeadow Medical, an Ashfield Company, part of UDG Healthcare plc.) for providing medical writing and editorial support. This support was funded by Novo Nordisk.

Authorship. All named authors meet the International Committee of Medical Journal Editors (ICMJE) criteria for authorship for this article, take responsibility for the integrity of the work as a whole, and have given their approval for this version to be published.
Prior Presentation. Parts of this study were presented as an oral presentation at the American Diabetes Association, 79th Scientific Sessions, June 7-11, 2019, San Francisco, CA, USA.

Disclosures. Hirotaka Watada has acted as an advisory board member for Novo Nordisk and as a speaker for Astellas Pharma, Sanofi, Mitsubishi Tanabe Pharma, Novo Nordisk, Kowa Pharmaceutical, AstraZeneca, Takeda Pharmaceutical, Novartis, Nippon Boehringer Ingelheim, Merck Sharp \& Dohme, Sumitomo Dainippon Pharma, Eli Lilly Japan, Sanwa Kagaku Kenkyusho, Ono Pharmaceutical, Kissei Pharmaceutical, and FUJIFILM Pharma and has received grants from Astellas Pharma, Sanofi, Mitsubishi Tanabe Pharma, Novo Nordisk Pharma, AstraZeneca, Takeda Pharmaceutical, Novartis Pharma, Nippon Boehringer Ingelheim, Merck Sharp \& Dohme, Sumitomo Dainippon Pharma, Eli Lilly Japan, Ono Pharmaceutical, Kyowa Hakko Kirin, Daiichi Sankyo, Terumo, Pfizer Japan, Mochida Pharmaceutical, Taisho Toyama Pharmaceutical, Johnson \& Johnson, and Kowa. Ankur Doshi has acted as an advisory board member for Pfizer, and is actively participating in clinical trials with Novo Nordisk, Pfizer, Sanofi, and Sanumed. Liana K. Billings has acted on an advisory board for Novo Nordisk, Eli Lilly, and Sanofi and as a speaker for Novo Nordisk. Lars Bardtrum is an employee and shareholder at Novo Nordisk A/S and has acted on an advisory board for Novo Nordisk, Eli Lilly, and Sanofi and as a speaker for Novo Nordisk. Bue F. Ross Agner is an employee and shareholder at Novo Nordisk A/S. Mattis Flyvholm Ranthe is a former employee and shareholder at Novo Nordisk A/S and is now employed by ALK.

Compliance with Ethics Guidelines. All procedures performed in studies involving human participants were in accordance with the ethical standards of the institutional and/or national research committee and with the 1964 Helsinki declaration and its later amendments or comparable ethical standards. Informed consent was obtained from all individual participants included in the study. 
Data Availability. The datasets generated during and/or analyzed during the current study are available from the corresponding author on reasonable request.

Open Access. This article is distributed under the terms of the Creative Commons Attribution-NonCommercial 4.0 International License (http://creativecommons.org/licenses/ by-nc/4.0/), which permits any noncommercial use, distribution, and reproduction in any medium, provided you give appropriate credit to the original author(s) and the source, provide a link to the Creative Commons license, and indicate if changes were made.

\section{REFERENCES}

1. Meece J. Basal insulin intensification in patients with type 2 diabetes: a review. Diabetes Ther. 2018;9:877-90.

2. Khunti K, Nikolajsen A, Thorsted BL, Andersen M, Davies MJ, Paul SK. Clinical inertia with regard to intensifying therapy in people with type 2 diabetes treated with basal insulin. Diabetes Obes Metab. 2016;18:401-9.

3. Buse JB, Vilsboll T, Thurman J, et al. Contribution of liraglutide in the fixed-ratio combination of insulin degludec and liraglutide (IDegLira). Diabetes Care. 2014;37:2926-33.

4. Lingvay I, Pérez Manghi F, Garcia-Hernandez P, et al. Effect of insulin glargine up-titration vs insulin degludec/liraglutide on glycated hemoglobin levels in patients with uncontrolled type 2 diabetes: the DUAL $\mathrm{V}$ randomized clinical trial. JAMA. 2016;315:898-907.

5. Billings LK, Doshi A, Gouet D, et al. Efficacy and safety of IDegLira versus basal-bolus insulin therapy in patients with type 2 diabetes uncontrolled on metformin and basal insulin: the DUAL VII randomized clinical trial. Diabetes Care. 2018;41: 1009-16.

6. Gough SC, Bode B, Woo V, et al. Efficacy and safety of a fixed-ratio combination of insulin degludec and liraglutide (IDegLira) compared with its components given alone: results of a phase 3, open-label, randomised, 26-week, treat-to-target trial in insulin-naive patients with type 2 diabetes. Lancet Diabetes Endocrinol. 2014;2:885-93.
7. Gough SC, Bode BW, Woo VC, et al. One-year efficacy and safety of a fixed combination of insulin degludec and liraglutide in patients with type 2 diabetes: results of a 26-week extension to a 26-week main trial. Diabetes Obes Metab. 2015;17: 965-73.

8. Linjawi S, Bode BW, Chaykin LB, et al. The efficacy of IDegLira (insulin degludec/liraglutide combination) in adults with type 2 diabetes inadequately controlled with a GLP-1 receptor agonist and oral therapy: DUAL III randomized clinical trial. Diabetes Ther. 2017;8:101-14.

9. Rodbard HW, Bode BW, Harris SB, et al. Safety and efficacy of insulin degludec/liraglutide (IDegLira) added to sulphonylurea alone or to sulphonylurea and metformin in insulin-naive people with type 2 diabetes: the DUAL IV trial. Diabet Med. 2017;34: 189-96.

10. Lingvay I, Perez Manghi F, Garcia-Hernandez P, et al. Effect of insulin glargine up-titration vs insulin degludec/liraglutide on glycated hemoglobin levels in patients with uncontrolled type 2 diabetes: the DUAL V randomized clinical trial. JAMA. 2016;315:898-907.

11. Harris SB, Kocsis G, Prager R, et al. Safety and efficacy of IDegLira titrated once weekly versus twice weekly in patients with type 2 diabetes uncontrolled on oral antidiabetic drugs: DUAL VI randomized clinical trial. Diabetes Obes Metab. 2017;19:858-65.

12. Philis-Tsimikas A, Billings LK, Busch R, et al. Superior efficacy of insulin degludec/liraglutide versus insulin glargine U100 as add-on to sodium-glucose co-transporter-2 inhibitor therapy: a randomized clinical trial in patients with uncontrolled type 2 diabetes. Diabetes Obes Metab. 2019;6:1399-408.

13. Aroda VR, Gonzalez-Galvez G, Gron R, et al. Durability of insulin degludec plus liraglutide versus insulin glargine U100 as initial injectable therapy in type 2 diabetes (DUAL VIII): a multicentre, openlabel, phase $3 \mathrm{~b}$, randomised controlled trial. Lancet Diabetes Endocrinol. 2019;7:596-605.

14. Watada H, Kaneko S, Komatsu M, et al. Superior HbA1c control with the fixed-ratio combination of insulin degludec and liraglutide (IDegLira) compared with a maximum dose of 50 units of insulin degludec in Japanese individuals with type 2 diabetes in a phase 3 , double-blind, randomized trial. Diabetes Obes Metab. 2019. https://doi.org/10. 1111/dom.13859.

15. Philis-Tsimikas A, Billings LK, Busch R, et al. Superior efficacy of insulin degludec/liraglutide versus insulin glargine U100 as add-on to sodium-glucose co-transporter- 2 inhibitor therapy: a randomized 
clinical trial in patients with uncontrolled type 2 diabetes. Diabetes Obes Metab. 2019;21:1399-408.

16. Balena R, Hensley IE, Miller S, Barnett AH. Combination therapy with GLP-1 receptor agonists and basal insulin: a systematic review of the literature. Diabetes Obes Metab. 2013;15:485-502.
17. Vedtofte L, Knop FK, Vilsboll T. Efficacy and safety of fixed-ratio combination of insulin degludec and liraglutide (IDegLira) for the treatment of type 2 diabetes. Expert Opin Drug Saf. 2017;16:387-96. 